\title{
The impact of intrahepatic cholestasis of pregnancy with hepatitis B virus infection on perinatal outcomes
}

This article was published in the following Dove Press journal:

Therapeutics and Clinical Risk Management

23 May 2014

Number of times this article has been viewed

Yun $\mathrm{Hu}$

Yi-Ling Ding

Ling Yu

Department of Obstetrics and Gynecology, The Second Xiangya Hospital, Central South University, Changsha, Hunan Province, People's Republic of China
Correspondence: Yi-Ling Ding Department of Obstetrics and Gynecology, The Second Xiangya Hospital, Central South University, 139 Renming zhong Road, Changsha 4I00II, Hunan, People's Republic of China Tel/fax +86 073। 852958I6 Email dingyiling_csu@163.com
Introduction: To investigate the impact of intrahepatic cholestasis of pregnancy (ICP) with hepatitis B virus (HBV) infection on perinatal outcomes.

Methods: In the study, 200 pregnant women were divided into four groups, including 50 cases with ICP and HBV infection, 50 cases with ICP, 50 cases with HBV infection, and 50 healthy pregnancies. The delivery process and perinatal outcomes were analyzed among different groups.

Results: When compared to the healthy pregnancy group, significantly increased rates of premature rupture of membranes, meconium-stained amniotic fluid, and cesarean section were observed in cases of ICP, HBV infection, or ICP patients with HBV $(P<0.05)$. Specifically, the rates of $\mathrm{HBV}$ infection in the newborn, fetal distress, neonatal asphyxia, and birth defects in the newborn, and infant Apgar scores were higher in ICP pregnancies with HBV $(56 \%, 48 \%$, $16 \%$, and $48 \%$, respectively) than in the other groups $(P<0.05)$.

Conclusion: ICP combined with HBV infection has a clear influence on perinatal infant outcomes.

Keywords: premature rupture of membranes, meconium-stained amniotic fluid, cesarean section, fetal distress, neonatal asphyxia, birth defects, Apgar scores

\section{Introduction}

Hepatitis B virus (HBV) infection and intrahepatic cholestasis of pregnancy (ICP) are common diseases in pregnancy. ICP results from abnormal metabolism of bile acids in the mother, often occurs in mid or late pregnancy, and is a pregnancy-specific liver disease. ICP is a minor complaint among mothers that abates quickly after parturition; however, ICP is associated with adverse fetal outcomes, such as premature rupture of membranes (PROM), meconium-stained amniotic fluid (MSAF), and fetal distress, contributing to neonatal asphyxia, preterm birth, and intrauterine death. ${ }^{1-6}$

HBV belongs to the family Hepadnaviridae and has a high infection rate, with about 600,000 patients dying of the disease worldwide every year. HBV infection has become an uncontrollable public health problem in developing countries. HBV infection triggers an autoimmune response, and ultimately leads to hepatic cell damage. Moreover, specific hormone level changes during pregnancy can place extra burden on the liver and aggravate liver disease. ${ }^{7-9} \mathrm{HBV}$ infection and ICP can affect the development of liver disease, but their relationship during pregnancy is not known. In present study, the authors analyzed the status of the perinatal infants in ICP-and/or HBV-infected pregnancy, in order to find out how ICP and HBV affect health, treatment, and prognosis in perinatal infants. 


\section{Materials and methods} Patients

Two hundred pregnancies with comparable clinical conditions were prospectively recruited, and divided equally into four groups. The ICP group included those who had skin pruritus, jaundice, increased serum bile acid levels, and slightly elevated liver transaminase, in accordance with the diagnostic criteria of ICP; the HBV infection group was made up of 50 pregnancies with positive hepatitis B surface antigen (HBsAg) during pregnancy; the ICP with HBV group was composed of 50 pregnancies with ICP who had positive $\mathrm{HBsAg}$, hepatitis e antigen ( $\mathrm{HBeAg}$ ), and hepatitis $\mathrm{B}$ core antibody ( $\mathrm{HBcAb})$; and the control group included 50 healthy pregnancies. The 200 pregnancies had all prenatal examinations and births in our hospital between January 2011 and February 2013 (age range: 21-40 years, median age: 27.7 years, median gestational week: 38.5 weeks). The general characteristics in the four groups made no statistically significant differences $(P>0.05$; Table 1$)$.

The study was approved by the Ethics Committee of the Second Xiangya Hospital of Central South University and informed consent was obtained from all subjects.

\section{Assessment method}

We monitored the rates of fetal intrauterine distress, neonatal asphyxia, and birth defects. Fetal intrauterine distress was judged according to the clinical diagnosis. Generally, fetal intrauterine distress can be diagnosed in accordance with any of the following symptoms: the degree of contamination of the amniotic fluid reaching II-III degrees, fetal heart rate $>160 \mathrm{bpm}$ or $<120 \mathrm{bpm}$ during the intervals of uterine contraction (severely abnormal fetal heart rate is $<100 \mathrm{bpm}$ or $>180 \mathrm{bpm}$ ), abnormal nonstress test (NST) baseline rate on electronic fetal monitor (including variation decreasing or disappearing, no reaction, decelerating in the late period, and frequent variable deceleration), and fetal movement fewer than three times per hour or fewer than half of the original number of movements after treatment.

Table I General clinical condition of the four groups

\begin{tabular}{lllll}
\hline Groups & $\mathbf{n}$ & $\begin{array}{l}\text { Weight } \\
\mathbf{( k g )}\end{array}$ & $\begin{array}{l}\text { Age } \\
\text { (years) }\end{array}$ & $\begin{array}{l}\text { Gestational } \\
\text { age (weeks) }\end{array}$ \\
\hline Control & 50 & $66.4 \pm 5.2$ & $28.2 \pm 5.8$ & $39.2 \pm 0.9$ \\
ICP & 50 & $64.7 \pm 6.8$ & $27.7 \pm 6.1$ & $38.9 \pm 0.7$ \\
HBV & 50 & $65.4 \pm 6.5$ & $26.3 \pm 6.4$ & $38.2 \pm 1.2$ \\
ICP with HBV & 50 & $61.5 \pm 7.6$ & $26.8 \pm 7.1$ & $37.4 \pm 1.6$ \\
\hline
\end{tabular}

Abbreviations: HBV, hepatitis B virus; ICP, intrahepatic cholestasis of pregnancy.
Neonatal asphyxia was decided by Apgar scores, scores 4-7 and 0-3 were regarded as mild and severe asphyxia, respectively. PROM and MSAF, and cesarean section rate were calculated during and after childbirth, respectively.

Birth defects were defined as dysplasia and physical abnormalities of the fetuses that already existed in the womb before birth; these include two types: deformity and dysfunction. Some birth defects are visible when the baby is born, called abnormalities, such as cleft lip and palate (harelip), lack of hands and feet, polydactylism, etc; while some defects are invisible and revealed gradually throughout the children's growth, such as simple mental retardation, phenylketonuria, progressive muscular dystrophy, etc.

\section{HBV examination}

The venous blood from the sick pregnant women was collected to detect HBV serum markers, including HBsAg, hepatitis B surface antibody (HBsAb), $\mathrm{HBeAg}$, hepatitis e antibody ( $\mathrm{HBeAb}$ ), and $\mathrm{HbcAb}$ in the Department of Clinical Laboratory. HBV markers were also examined in newborns suspected to be infected 24-48 hours after birth.

\section{Statistical analysis}

Statistical analysis was performed using SPSS software (v17.0; IBM Corporation, Armonk, NY, USA). Statistical significance was determined by Fisher's exact probabilities, chi-square tests, and Student's $t$-test according to the data type. $P<0.05$ was considered to be statistically significant.

\section{Results \\ The influence of ICP with HBV infection on delivery method}

As shown in Table 2, the occurrence rates of PROM and MSAF were higher in the infected groups than in the control group $(P<0.05)$, while there was no statistically significant

Table 2 Methods of childbirth in each group

\begin{tabular}{lllll}
\hline Groups & $\mathbf{n}$ & $\begin{array}{l}\text { PROM, } \\
\text { MSAF }\end{array}$ & $\begin{array}{l}\text { Cesarean } \\
\text { section }\end{array}$ & Eutocia \\
\hline Control & 50 & $3(6.0)$ & $8(16.0)$ & $42(84.0)$ \\
ICP & 50 & $13(26.0)^{*}$ & $37(74.0)^{*}$ & $12(24.0)$ \\
HBV & 50 & $11(22.0)^{* *}$ & $16(32.0)^{* *}$ & $32(64.0)$ \\
ICP with HBV & 50 & $26(52.0)^{* * *}$ & $47(94.0)^{* * *}$ & $4(8.0)$ \\
\hline
\end{tabular}

Notes: All numbers are $\mathrm{n}(\%) ; * P<0.05, \mathrm{ICP}$ group vs control group; $* * P<0.05$, $\mathrm{HBV}$ group vs control group; ${ }^{* * * P}<0.05$, IPC with $\mathrm{HBV}$ group vs control group. Abbreviations: $\mathrm{HBV}$, hepatitis $B$ virus; ICP, intrahepatic cholestasis of pregnancy; MSAF, meconium-stained amniotic fluid; PROM, premature rupture of membranes. 
difference between the ICP with HBV infection group and the other groups $(P>0.05)$.

\section{The influence of ICP with HBV infection on $\mathrm{HBV}$ vertical transmission from mother to child}

In Table 3, all the 50 newborns in the control group and 50 newborns in the ICP group were not HBV infected. Only ten of the 50 newborns in the HBV group were found to be HBV positive and the rate of $\mathrm{HBV}$ intrauterine infection was $10 \%$. In the ICP with HBV infection group, 28 of the 50 newborns were HBV positive and the rate of intrauterine infection was $56 \%$.

\section{The relationship between ICP with $\mathrm{HBV}$ infection and fetal distress and neonatal asphyxia}

As shown in Table 4, the rate of fetal distress in the ICP group, HBV group, and ICP with HBV infection group were $26 \%$ $(13 / 50), 14 \%(7 / 50)$, and $60 \%(30 / 50)$, respectively. This rate was only $6 \%(3 / 50)$ in the control group $(P<0.05)$. In addition, when ICP is combined with HBV infection, the occurrence of fetal distress increased significantly $(P<0.05)$.

\section{The relationship between ICP with $\mathrm{HBV}$ infection and Apgar scores}

The rates of neonatal asphyxia (Apgar score: 0-7) among the four groups are summed up in Table 5. Neonatal asphyxia in the ICP with $\mathrm{HBV}$ infection group was more severe than in the other three groups $(P<0.05)$. There was no statistically significant difference between the ICP and HBV group on neonatal asphyxia, when compared with the control group $(P>0.05)$.

\section{The influence of ICP with HBV infection on birth defect rate}

In the ICP with HBV infection group, three newborn congenital abnormalities and five full-term neonates with low birth weight were found. The ICP group and the control group

Table 3 The rates of HBV infection in infants

\begin{tabular}{llll}
\hline Groups & $\mathbf{n}$ & HBV infection & \\
\cline { 3 - 4 } & & $\mathbf{( + )}$ & $\mathbf{( - )}$ \\
\hline Control & 50 & $0(0)$ & $50(100)$ \\
ICP & 50 & $0(0)$ & $50(100)$ \\
HBV & 50 & $5(10)$ & $45(90)$ \\
ICP with HBV & 50 & $28(56)^{*}$ & $22(44)$ \\
\hline
\end{tabular}

Notes: All numbers are $n(\%) ;{ }^{*}<0.05$, ICP with HBV group vs other groups.

Abbreviations: $\mathrm{HBV}$, hepatitis $B$ virus; ICP, intrahepatic cholestasis of pregnancy.
Table 4 The rate of fetal distress in the four groups

\begin{tabular}{lll}
\hline Groups & $\mathbf{n}$ & Rate of fetal distress \\
\hline Control & 50 & $3(6)$ \\
ICP & 50 & $13(26)$ \\
HBV & 50 & $7(14)$ \\
ICP with HBV & 50 & $30(60)^{*}$ \\
\hline
\end{tabular}

Notes: All numbers are $n(\%) ;{ }^{*}<0.05, I C P$ with HBV group vs other groups. Abbreviations: $\mathrm{HBV}$, hepatitis $B$ virus; ICP, intrahepatic cholestasis of pregnancy.

had one newborn congenital abnormality each. The HBV infection group had one full-term neonate with low birth weight. Thus, the occurrence rate of newborn congenital abnormalities and full-term neonates with low birth weight in the ICP with HBV infection group was apparently higher than that in the other three groups (Table 6; $P<0.05$ ).

\section{Discussion}

ICP is one of the most common diseases during the pregnancy, next to HBV infection. It mainly occurs in mid or late pregnancy and is caused by the abnormal metabolism of bile acid in the mother's body. ${ }^{10,11}$ ICP is a disease that can specifically lead to fetus or newborn diseases during the perinatal period. The biochemical characteristics of ICP are increased serum bile acid levels with mild abnormal aminotransferase, and increased bilirubin. ${ }^{12-14} \mathrm{ICP}$ is a transient benign symptom to most mothers, but to the fetus, it can lead to serious consequences, including preterm birth, asphyxia, and other severe consequences. ${ }^{15}$ In the People's Republic of China, the HBsAg positive population is more than $90,000,000$ individuals. ${ }^{16}$ Epidemiological investigations have shown that the rate of HBV in pregnant women is $10.2 \%$; moreover, the positive rate of HBsAg among infected pregnancies can reach up to $20 \%-30 \%$, and can even reach above $30 \%$ between the ages of 20-25 years in the mother. ICP with HBV infection often causes placental chorionic vascular lesions, leading to placenta function defects, aggravation of cholestasis, significant hypoxia, fetal distress, fetal growth restriction, preterm birth or stillbirth, and other severe negative effects; therefore, these pregnancies are regarded as high risk. ${ }^{16}$

Table 5 Infant Apgar scores in the four groups

\begin{tabular}{lllll}
\hline Groups & $\mathbf{n}$ & \multicolumn{3}{l}{ Apgar scores } \\
\cline { 2 - 4 } & & $\mathbf{0 - 3}$ & $\mathbf{4 - 7}$ & $>\mathbf{7}$ \\
\hline Control & 50 & $0(0)$ & $2(4)$ & $48(96)$ \\
ICP & 50 & $2(0)$ & $4(8)$ & $44(92)$ \\
HBV & 50 & I (2) & $6(12)$ & $43(86)$ \\
ICP with HBV & 50 & $10(20)^{*}$ & $16(32)^{*}$ & $24(48)$ \\
\hline
\end{tabular}

Notes: All numbers are $\mathrm{n}(\%) ; * P<0.05$, ICP with HBV group vs other groups.

Abbreviations: HBV, hepatitis B virus; ICP, intrahepatic cholestasis of pregnancy. 
Table 6 The rate of birth defects in the four groups

\begin{tabular}{lll}
\hline Groups & $\mathbf{n}$ & Rate of birth defect \\
\hline Control & 50 & $0(0)$ \\
ICP & 50 & $0(0)$ \\
HBV & 50 & $\mathrm{I}(2)$ \\
ICP with HBV & 50 & $8(16)^{*}$ \\
\hline
\end{tabular}

Notes: All numbers are $\mathrm{n}(\%) ; * P<0.05, \mathrm{ICP}$ with HBV group vs other groups. Abbreviations: HBV, hepatitis $B$ virus; ICP, intrahepatic cholestasis of pregnancy.

Recent studies have shown that ICP is connected to heredity, immunity, and estrogen, as well as the environment, with the mechanism of action still unclear. ${ }^{17}$ The present study found no statistically significant difference on the delivery method between the ICP group, the HBV infection group, and the control group. However, in the ICP with HBV infection group, most of the pregnancies were $\mathrm{HBsAg}, \mathrm{HBeAg}$, and $\mathrm{HBcAb}$ positive, and $\mathrm{PROM}$ and MSAF were more apparent. Therefore, it is recommended for the mother to opt for a cesarean section. The finding that the delivery method does not affect HBV vertical transmission from mothers to their infants has been confirmed in an expanded study examining over 300 individuals. ${ }^{4}$ Our study found that the transmission rate from mothers to their infants is $20 \%$, in accordance with previous data $(15.5 \%-23.0 \%))^{4,12,16}$ However, ICP with HBV infection, especially when the $\mathrm{HBsAg}, \mathrm{HBeAg}$, and $\mathrm{HBcAb}$ were all positive, could severely affect the pregnancy and maternal and child health during the delivery. Moreover, HBV intrauterine infection rate reached $100 \%$ and infected infants would remain infected with the virus, with an apparently increasing occurrence rate of chronic hepatitis, and cirrhosis and cancer of the liver. Most HBV infection pregnancies have no clinical symptoms, or abnormal hepatic or coagulation functions. It has little influence on fetal growth in the uterus. However, HBV infection often occurs in late pregnancy, making it easier to result in PROM and MSAF, especially in the ICP and HBsAg positive pregnancies.

Some studies have suggested that the placental barrier can partially block HBV, while the fetal infection rate of HBsAg positive carriers is $67.21 \%$ (46 out of 61 ). ${ }^{18}$ Another study found that HBV infection of villi capillary endothelial cells is closely related to $\mathrm{HBV}$ intrauterine infection. ${ }^{19} \mathrm{HBV}-$ infected placentas are more likely to have vascular lesions in the chorion, including swelling of the endothelial cells, lumen narrowing, and fibrinoid necrosis of the basement membrane. ${ }^{19}$ Placental lesions easily cause fetal distress and fetal anoxia suffocation. ${ }^{20}$ Our results showed that, in the ICP and HBV infection groups, fetal distress and neonatal asphyxia rates were higher in than the control group, while the ICP with HBV infection group had the highest incidence rates, with the difference being statistically significant from the other groups. Some researchers think that mother-tochild transmission of HBV can increase the occurrence of fetal distress and ICP in pregnancy; ${ }^{21}$ our study is not large enough to draw conclusions on whether HBV infection increases ICP or whether ICP can promote $\mathrm{HBV}$ infection recurrence or aggravate HBV infection symptoms. Some researchers believe that deposition of bile acid can increase HBV replication and metabolic disturbance, which could aggravate or induce HBV infection..$^{22}$ In addition, one recent study confirmed that the HBV or hepatitis delta virus membrane receptor is bile acid of sodium/taurocholic acid transporters $\mathrm{Na}^{+}$-taurocholate cotransporting polypeptide (NTCP) ${ }^{23}$ In conclusion, we propose that ICP with HBV infection increases intrahepatic metabolism disorder and is the preliminary cause of intrauterine hypoxia and bile acid toxicity; on the other hand, it can cause deposition of bile acid activated aggravate or cause HBV infection, placental chorionic vascular damage, and affect placental function and change its permeability. HBV spreads easily intrauterinally. In addition, the virus and cholic acid factors can aggravate intrauterine hypoxia and cholestasis, causing fetal maladjustment, fetal intrauterine distress, and even suffocation.

Although this study showed that the incidence of birth defects in the ICP with HBV group was higher than in the control group, we could not conclude that ICP with HBV infection is the primary cause since many factors can cause birth defects, which cannot be ruled out in the present study.

Therefore, based on our observations, we hold the opinion that ICP with HBV infection not only has serious effects on the newborn, but also aggravates ICP and virus infection symptoms in mothers. Therefore, it is necessary to emphasize the examination of liver function and fetal intrauterine monitoring during the pregnancy and delivery. Active treatment to prevent neonatal asphyxia and HBV infection should be considered.

\section{Disclosure}

The authors report no conflicts of interest in this work.

\section{References}

1. Turunen K, Helander K, Mattila KJ, Sumanen M. Menopause after a history of intrahepatic cholestasis of pregnancy. Menopause. 2013;20(11):1200-1203.

2. Mölsä A, Turunen K, Mattila KJ, Sumanen M. Unnecessary confusion about family planning after intrahepatic cholestasis of pregnancy. Contraception. 2012;86(6):639-644.

3. Wikström Shemer E, Thorsell M, Östlund E, Blomgren B, Marschall HU. Stereological assessment of placental morphology in intrahepatic cholestasis of pregnancy. Placenta. 2012;33(11):914-918. 
4. Restellini S, Martinez de Tejada B, Spahr L, Giostra E. [Management of liver diseases during pregnancy]. Rev Med Suisse. 2013;9(396): 1577-1580, 1582-1583. French.

5. Martinefski M, Contin M, Samassa P, Di Carlo MB, Lucangioli S, Tripodi V. The importance of analytical methodology in accurate diagnosis and monitoring of intrahepatic cholestasis of pregnancy. Int J Gynaecol Obstet. 2013;123(1):78-79.

6. Geenes V, Chappell LC, Seed PT, Steer PJ, Knight M, Williamson C. Association of severe intrahepatic cholestasis of pregnancy with adverse pregnancy outcomes: a prospective population-based case-control study. Hepatology. 2014;59(4):1482-1491.

7. Turunen K, Helander K, Mattila KJ, Sumanen M. Intrahepatic cholestasis of pregnancy is common among patients' first-degree relatives. Acta Obstet Gynecol Scand. 2013;92(9):1108-1110.

8. Floreani A, Caroli D, Lazzari R, et al. Intrahepatic cholestasis of pregnancy: new insights into its pathogenesis. J Matern Fetal Neonatal Med. 2013;26(14):1410-1415.

9. Zhou F, He MM, Liu ZF, Zhang L, Gao BX, Wang XD. Expression of corticotrophin-releasing hormone and its receptor in patients with intrahepatic cholestasis of pregnancy. Placenta. 2013;34(5): 401-406.

10. Medina Lomelí JM, Jáuregui Meléndrez RA, Medina Castro N, Medina Castro D. [Intrahepatic cholestasis of pregnancy: review]. Ginecol Obstet Mex. 2012;80(4):285-288.

11. Turunen K, Mölsä A, Helander K, Sumanen M, Mattila KJ. Health history after intrahepatic cholestasis of pregnancy. Acta Obstet Gynecol Scand. 2012;91(6):679-685.

12. Pusl T, Beuers U. Intrahepatic cholestasis of pregnancy. Orphanet $J$ Rare Dis. 2007;29(2):26.

13. Lu J, Qi H. Sudden fetal death in a patient with intrahepatic cholestasis of pregnancy complicated with gestational diabetes mellitus. Arch Gynecol Obstet. 2013;287(1):179-182.
14. Lee RH, Incerpi MH, Miller DA, Pathak B, Goodwin TM. Sudden fetal death in intrahepatic cholestasis of pregnancy. Obstet Gynecol. 2009;113(2 Pt 2):528-531.

15. Arrese M, Reyes H. Intrahepatic cholestasis of pregnancy: a past and present riddle. Ann Hepatol. 2006;5(3):202-205.

16. Chen LZ, Zhou WQ, Zhao SS, Liu ZY, Wen SW. A nested case-control study of maternal-neonatal transmission of hepatitis B virus in a Chinese population. World J Gastroenterol. 2011;17(31):3640-3644.

17. Terrault NA, Jacobson IM. Treating chronic hepatitis B infection in patients who are pregnant or are undergoing immunosuppressive chemotherapy. Semin Liver Dis. 2007;27 Suppl 1:18-24.

18. Giles ML, Visvanathan K, Lewin SR, Sasadeusz J. Chronic hepatitis B infection and pregnancy. Obstet Gynecol Surv. 2012;67(1):37-44.

19. Kowalik-Mikołajewska B, Aniszewska M, Pokorska-Śpiewak M. Mother-to-child HBV transmission - atypical course of hepatitis B in an infant. Med Wieku Rozwoj. 2012;16(2):149-153.

20. Ray K. IBS: linaclotide approved for constipation-predominant IBS. Nat Rev Gastroenterol Hepatol. 2012;9(11):616.

21. Liu ZY, Li XY, Yan XM, Chen LZ. Nested case-control study on the influence factors of perinatal stage transmission of hepatitis B virus. Zhong Nan Da Xue Xue Bao Yi Xue Ban. 2007;32(3):451-454.

22. Kim HY, Cho HK, Choi YH, Lee KS, Cheong J. Bile acids increase hepatitis B virus gene expression and inhibit interferon-alpha activity. FEBS J. 2010;277(13):2791-2802.

23. Yan $\mathrm{H}$, Zhong G, Xu G. Sodium taurocholate cotransporting polypeptide is a functional receptor for human hepatitis B and D virus. Elife. 2012;1:e00049.
Therapeutics and Clinical Risk Management

\section{Publish your work in this journal}

Therapeutics and Clinical Risk Management is an international, peerreviewed journal of clinical therapeutics and risk management, focusing on concise rapid reporting of clinical studies in all therapeutic areas, outcomes, safety, and programs for the effective, safe, and sustained use of medicines. This journal is indexed on PubMed Central, CAS,

\section{Dovepress}

EMBase, Scopus and the Elsevier Bibliographic databases. The manuscript management system is completely online and includes a very quick and fair peer-review system, which is all easy to use. Visit http://www.dovepress.com/testimonials.php to read real quotes from published authors.

Submit your manuscript here: http://www.dovepress.com/therapeutics-and-clinical-risk-management-journal 